\title{
The description of a new species of Niphargus from Iran based on morphological and molecular data
}

\author{
Somayeh Esmaeili-Rineh', Seyyed Ahmad Mirghaffari', Mozafar Sharifi' \\ I Department of Biology, Faculty of Science, Razi University, Kermanshah, Iran \\ Corresponding author: Somayeh Esmaeili-Rineh (sesmaeili@razi.ac.ir)
}

Academic editor: O. Moldovan | Received 22 November 2016 | Accepted 9 March 2017 | Published 7 April 2017

http://zoobank.org/ECD4760E-078B-47BE-81FB-9A5390AF045F

Citation: Esmaeili-Rineh S, Mirghaffari SA, Sharifi M (2017) The description of a new species of Niphargus from Iran based on morphological and molecular data. Subterranean Biology 22: 43-58. https://doi.org/10.3897/subtbiol.22.11286

\begin{abstract}
The freshwater amphipods of the genus Niphargus Schiödte, 1849 are widespread in subterranean waters of the western Palearctic. The eastern half of the genus range has been incompletely studied despite the presence of karstic areas and large aquifers. In this paper, we describe a new species from Hamedan Province in Iran and name it as $N$. hakani sp. n. This species hypothesis is based on the analysis of morphological characters and $28 \mathrm{~S}$ ribosomal DNA sequences. The taxonomic status of the new species within the genus is discussed in comparison to the known Iranian species. Results revealed that this species is phylogenetically close to $N$. khwarizmi and is morphologically similar to $N$. borisi.
\end{abstract}

\section{Keywords}

Niphargus, Hamedan Province, Taxonomy, 28SrDNA, Iran

\section{Introduction}

The members of genus Niphargus Schiödte, 1849 are widespread in subterranean freshwaters of West Palearctic (Meleg et al. 2013). Most of the species of this genus occur in subterranean waters and constitute an important part of biodiversity in this environment (Fišer 2012). Few studies of this genus in the Middle East indicate that about 24 species live in this area, representing only a small fraction of over 350 known species. 
Iran presents the eastern-most boundary of the Niphargus range. The first species is record of $N$. valachicus Dobreanu \& Manolache, 1933 in Iran, a widely distributed species (Karaman 1998). According to previous studies, 10 species have been found in the northern and western parts of Iran. Species inventory includes $N$. valachicus, $N$. khayyami Hekmatara et al., 2013, N. khwarizmi Hekmatara et al., 2013, N. alisadri Esmaeili-Rineh \& Sari, 2013, N. daniali Esmaeili-Rineh \& Sari, 2013, N. bisitunicus Esmaeili-Rineh et al., 2015, N. borisi Esmaeili-Rineh et al., 2015, N. darvishi EsmaeiliRineh et al., 2015, N. sharifi $i$ Esmaeili-Rineh et al., 2015, and N. kermanshahi EsmaeiliRineh et al., 2016. In this paper, we describe a new species from karstic spring in north of Hamedan Province.

\section{Materials and methods}

\section{Morphologic and morphometric studies}

The specimens were collected using a small hand net in Kheder-Goli Spring in Hakan Village close to Razan City (see Figure 1). Details of individual landmarks were measured according to Fišer et al. (2009) and then mounted on slides in a Euparal medium. Digital photos were taken with an Olympus LABOMED iVu 7000 camera fitted on an LABOMED Lx500 stereomicroscope. Measurements and counts were made using the computer program ProgRes CapturePro 2.7. The specimens used for the present study are deposited in the Zoological Collection of Razi University (ZCRU).

\section{Molecular and phylogenetic analyses}

Genomic DNA was isolated from a part of animal using the Tissue Kits (GenNet$\mathrm{Bio}^{\mathrm{TM}}$ ), according to the manufacturer's instructions (Seoul, South Korea). Amplification and sequencing of the $28 \mathrm{~S}$ ribosomal DNA (rDNA) fragment were performed using the forward primer from Verovnik et al. (2005) and the reverse primer from Zakšek et al. (2007).

PCR amplifications were done in $25 \mu$ l volumes, containing, $2.5 \mu \mathrm{l}$ of $10 \times$ PCR buffer (100 mM Tris-HCl (pH 8.8), (500 mM KCl), $0.2 \mu \mathrm{l}$ of each primer $(10 \mu \mathrm{M})$, $0.5 \mu \mathrm{l}$ of dNTP $(10 \mathrm{mM}), 0.75 \mu \mathrm{MgCl}_{2}(50 \mathrm{mM}), 50-100 \mathrm{ng}$ of genomic DNA template, and 1 unit of Taq DNA polymerase. Cycling parameters were as follows: initial denaturation of $94^{\circ} \mathrm{C}$ for $7 \mathrm{~min}, 35$ subsequent cycles of $94^{\circ} \mathrm{C}$ for $45 \mathrm{~s}, 55^{\circ} \mathrm{C}$ for $30 \mathrm{~s}$ and $72^{\circ} \mathrm{C}$ for $1 \mathrm{~min}$, and a final extension of $72^{\circ} \mathrm{C}$ for $7 \mathrm{~min}$. Sequencing reactions were done in Macrogen Korea Laboratories.

In order to figure out the phylogenetic position of the new discovered species, we analyzed the acquired sequences (GenBank accession numbers are KY629001 and KY629002) within the data set of Esmaeili-Rineh et al. (2015a) and Esmaeili-Rineh et al. (2016). Three species including Synurella ambulans (F. Müller, 1846), Obesogam- 


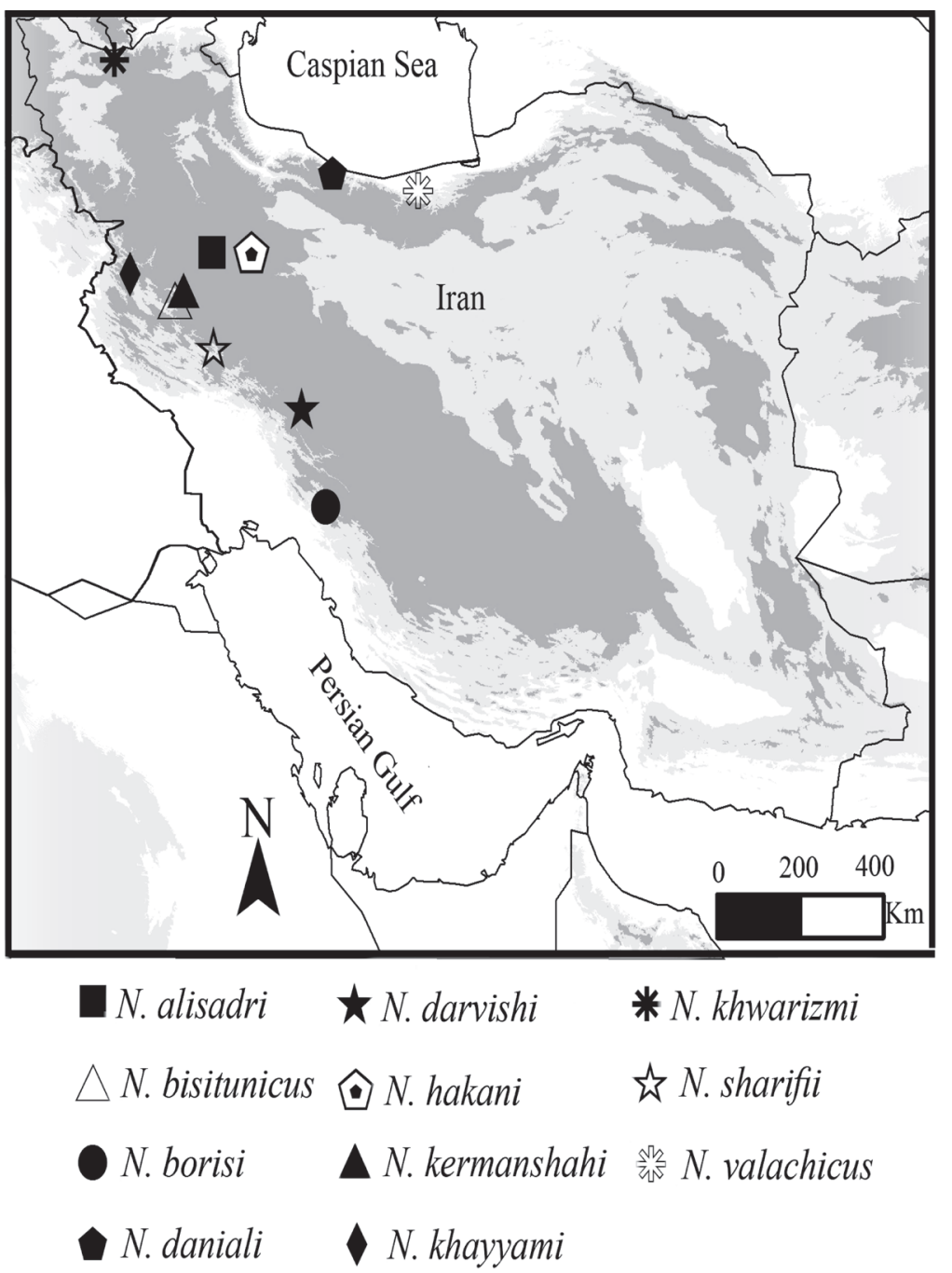

Figure I. Distribution map of the members of genus Niphargus in Iran.

marus crassus (Sars G.O., 1894), and Gammarus fossarum Koch, 1836, were used as outgroup (KF719240, KF719242 and KF71924). All the sequences were edited and aligned using ClustalW (Thompson et al. 1994), as implemented in the Bioedit program sequence alignment editor (Hall 1999) using the default settings.

Phylogenetic reconstruction was performed using the Bayesian inferences in MRBAYES, version 3.1.2 (Huelsenbeck and Ronquist 2001, Ronquist and Huelsenbeck 2003). The Bayesian inferences analysis used the TVM+G model of nucleotide substitution. Estimates for the model parameters included estimated base frequencies $\mathrm{A}=$ $0.1949 ; \mathrm{C}=0.2733 ; \mathrm{G}=0.2807 ; \mathrm{T}=0.2511$ and gamma distribution shape parameter $(\alpha=0.3650)$ that was selected as the most appropriate substitution model using 
the Akaike information criteria $(-\operatorname{lnL}=8493.8093 ; \mathrm{AIC}=17215.6186)$ implemented in jModelTest, version 0.1.1 (Posada 2008).

To assess interspecific divergence between the Iranian species of Niphargus, we calculated the genetic distances corrected with Kimura two-parameter (K2P) model (Kimura 1980) as implemented in MEGA ver. 5 (Tamura et al. 2011).

Bayesian Inference was performed with two simultaneous runs and four search chains within each run (three heated chains and one cold chain) for 10,000,000 generations, sampling trees every 1000 generations. The first 2500 sampled trees were discarded as burn-in, and subsequent tree likelihoods were checked for convergence in Tracer 1.5.0 (Rambaut and Drummond 2009). A consensus tree with posterior probabilities was generated and visualized using the FigTree v1.4.0 software. Data on analyzed species are available in the Electronic Supplement of Esmaeili-Rineh et al. (2015a).

\section{Results}

\section{Systematics}

Order Amphipoda Latreille, 1816

Suborder Senticaudata Lowry \& Myers, 2013

Family Niphargidae Bousfield, 1977

Genus Niphargus Schiödte, 1849

\section{Niphargus hakani sp. $\mathrm{n}$. http://zoobank.org/13DEBDBC-0EF8-44C3-AC3E-A5F2ADDE6F17}

Material examined and type locality. Holotype, male specimen $(9 \mathrm{~mm})$ from KhederGoli spring, Razan city, Hamedan Province, Iran; coordinates $35^{\circ} 27^{\prime} \mathrm{N}, 49^{\circ} 07^{\prime} \mathrm{E}$. Specimens were collected by S. A. Mirghaffari in September 2014. Holotype with two paratypes is stored under catalogue number ZCRU Amph.1010 in the Zoological Collection of Razi University, Iran (ZCRU).

Diagnosis. At the base of uropod I observed only one robust seta. The palpus of maxilla I is slightly longer than outer lobe. Urosomites I-III bear two, five and two robust setae on dorso-lateral margin. Epimeral plates distinctly pointed and have three and four robust setae in ventral margin of plates II-III. The propodi of gnathopods I-II are trapezoid. Dactylus of gnathopod I dose not reach to posterior margin of propodus. Third article of mandibular palp bears a single group of two A-setae.

Description of holotype. Total length of specimen $9 \mathrm{~mm}$. Body strong and stout. Head length $11 \%$ of body length (Figure 2). Antennae I (Figure 2A) 0.6 of body length. Peduncular articles 1-3 progressively shorter; peduncular articles 2: 3 (ratio $1: 0.75$ ); main flagellum with 19 articles (most of which with short setae); accessory flagellum biarticulated and reaching 1/3 of article 4 of main flagellum, both articles with two simple setae, respectively (Figure $2 \mathrm{~A}$ ). Length ratio antenna I : II as $1: 0.46$. 


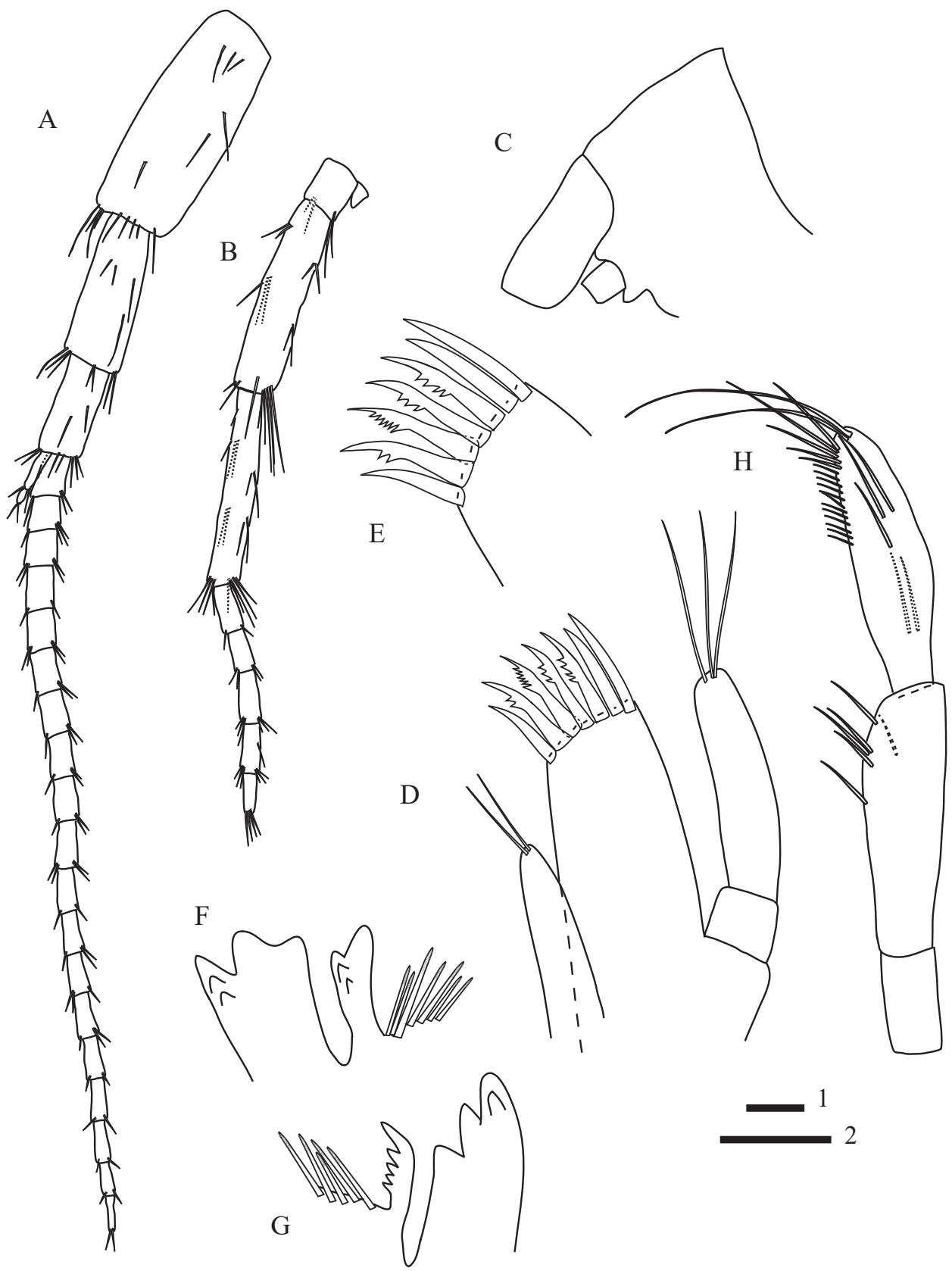

Figure 2. Niphargus hakani sp. n., male 9 mm (holotype, ZCRU Amph.1010). A Antenna I B Antenna II C Head D-E Maxilla I F Left mandible. G Right mandible. H Mandibular palp. Scale bars: $1=0.25$ $\mathrm{mm}$ (F-G). $2=0.5 \mathrm{~mm}$ (C-E, H). $3=1 \mathrm{~mm}$ (A-B). 
Peduncular article 4 slightly as long as article 5, each with seven groups of simple setae; flagellum with five articles. Length of flagellum: length of peduncle article $4+5$ as $0.57: 1$ (Figure 2B).

Labium (Figure 3D) with inner lobes and setae on the tip of lobes. Inner plate of maxilla I with two long simple setae; outer plate with seven bi-, pluri or without lateral projections; palp biarticulated, slightly longer than outer lobe, with three long distal simple setae (Figure 2D-E). Both plates of maxilla II with numerous distal simple setae (Figure 3E).

Incisor in left mandible with five teeth, lacinia mobilis with four teeth; seven setae with lateral projections between lacinia and triturative molar (Figure 2F). Incisor in right mandible with four teeth, lacinia mobilis pluritooth; five setae with lateral projections between lacinia and triturative molar (Figure 2G). Mandibular palp articles in ratio $1: 2: 3$ as $1: 2.46: 2.76$. The proximal article has no setae, the second article with six setae along inner margin and the third article with one group of two A-setae, two groups of B-setae, no C-setae, $15 \mathrm{D}$-setae and four E-setae (Figure 2H).

Maxilliped with short inner plate on which are four distal robust setae intermixed with five distal simple setae; outer plate exceeding half of the posterior margin of palp article 2, with 11 robust setae along inner margin and three simple setae distally. Palp article 3 of maxilliped with one proximal, inner and outer group of long simple setae at outer margin; terminal article of palp with one simple seta at outer margin, nail shorter than pedestal (Figure 3C).

Coxa of gnathopod I shorter than gnathopod II. Coxa I rectangular, longer than broad, ventral to anterior margin with four and three simple setae, respectively. Basis with setae on anterior and posterior margins; ischium and merus with posterior group of setae. Carpus with one group of three setae anterodistally, a bulge with long simple setae; carpus 0.42 of basis length and 0.79 of propodus length. Propodus slightly longer than broad; anterior margin with seven setae in two groups in addition to anterodistal group of six simple setae. Palm slightly convex, with one strong long palmar robust seta, one short supporting robust seta on inner surface and two robust setae with lateral projections on outer surface; two simple setae under supporting robust seta in palmar corner. Dactylus not reaching posterior margin of propodus, outer and inner margins with a row of three and five simple setae, respectively; nail short, 0.23 of total dactylus length (Figure 3A).

Coxa of gnathopod II slightly rounded, with six setae along antero-ventro-posterior margins. Basis with setae in groups and single setae along anterior and posterior margins; posterior margins of ischium and merus with one posterior group of setae each. Carpus 0.43 of basis length and 0.67 propodus length. Carpus with one group of four setae anterodistally. Propodus in gnathopod II larger than gnathopod I, trapezoid shape and broader than long; anterior margin with seven setae in one group in addition to anterodistal group of six simple setae. Palm nearly convex, with one strong palmar robust seta, one supporting robust seta without lateral projections on inner surface, and one robust seta with lateral projections on outer surface; two setae under supporting robust setae in palmar corner. Dactylus reaching posterior margin of propodus, 


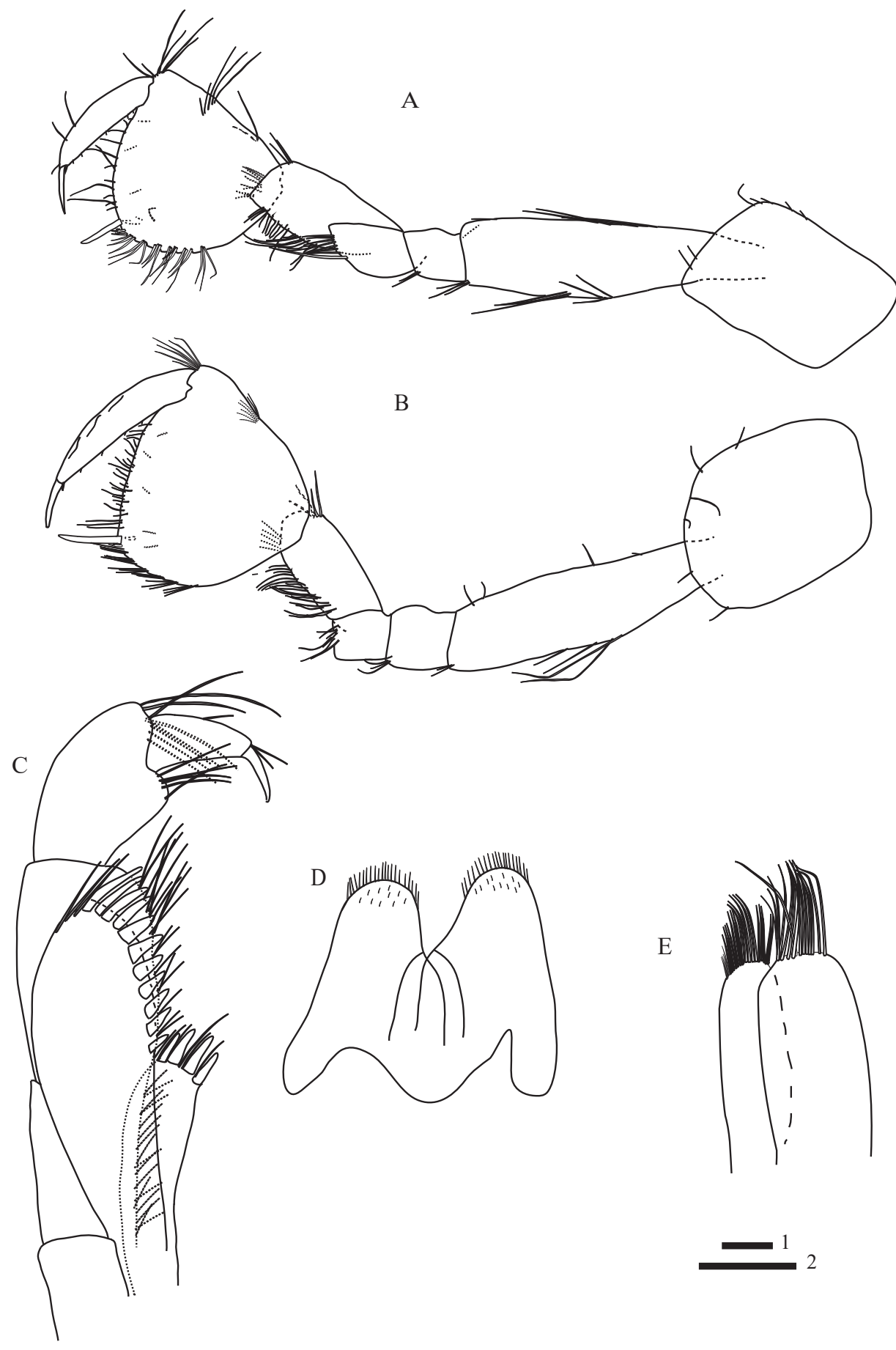

Figure 3. Niphargus hakani sp. n., male $9 \mathrm{~mm}$ (holotype, ZCRU Amph.1010). A Gnathopod I B Gnathopod II C Maxilliped D Labium E Maxilla II. Scale bars: 1=0.5 mm (C-E). 2=1 mm (A-B). 
outer and inner margins of dactylus with three and four simple setae, respectively. Nail length 0.25 of total dactylus length (Figure 3B).

Coxa III rectangular, length to width ratio as $1.29: 1$; antero-ventral margin with five simple setae. Coxa IV rectangular, length to width ratio as $1: 1.04$, antero-ventral margin with seven simple setae, posterior concavity shallow and approximately 0.1 of coxa width (Figure 4A-B). Coxa $\mathrm{V}$ with anterior lobe, with five and three simple setae on anterior and posterior lobe, respectively. Coxa VI with anterior lobe, with one simple seta on posterior lobe. Coxa VII with one simple seta (Figure 4C-E).

Pereopod III : IV lengths ratio as $1: 1.35$ (Figure 4A-B). Dactylus IV short, length of dactylus 0.40 of propodus, nail shorter than pedestal (Figure 4B). Pereopods V: VI: VII length ratios as $1: 1.35: 1.30$, respectively. Pereopod VII 0.63 of body length. Pereopod bases V-VI each with seven simple setae along posterior margin and six and seven groups of robust setae along anterior margins, respectively. Pereopod basis VII with 10 simple setae and six groups of robust setae along posterior and anterior margins, respectively (Figure 4C-E). Postero-ventral lobe of ischium in pereopods V-VII developed. Ischium, merus and carpus in pereopods V-VII with several groups of robust and simple setae along anterior and posterior margins; propodus of pereopod VII longer than these in V-VI, dactyli of pereopods V-VII with one robust and one short simple seta at the base of nail on inner margin, nail length of pereopod VII 0.29 of total dactylus length (Figure 4C-E).

Epimeral plates I-III (Figure 5G) with angular postero-ventral corner, anterior and ventral margins convex; postero-ventral corners of plates I-III with one robust seta each, and with two, three and two simple setae posteriorly, respectively. Epimeral plates II-III with three and four robust setae along of ventral margins, respectively. Peduncle of pleopod I with one simple seta and two-hooked retinacles at distal part of inner margin (Figure 5A); peduncle of pleopods II-III with two-hooked retinacles at distal part of inner margin; rami of pleopods I-III each with seven to 10 articles (Figure 5A-C).

Pereonites I-VI without setae. Pereonite VII with two simple setae. Pleonites I-III each with one long simple seta along dorsal surface. Urosomites I-III with two, five and two robust setae laterally, respectively.

Peduncle of uropod I with six and three large robust setae along dorsolateral and dorsomedial margins, respectively. Rami of uropod I with equal length (ratio $1: 1$ ); inner ramus with three groups of robust setae laterally and five robust setae distally; outer ramus with three groups of six robust setae laterally and five robust setae distally (Figure 5D). Outer ramus in uropod II longer than inner, both rami with lateral and distal long robust setae (Figure 5E). Uropod III long, almost 0.45 of body length. Peduncle of uropod III with five robust setae, Outer ramus biarticulated, distal : proximal article as $1: 1.92$. The proximal article of outer ramus bearing five groups of robust setae along inner and outer margins (Figure 5F); distal article with simple setae laterally and seven simple setae distally. Inner ramus short, with one robust and one simple distal seta. Telson two times as long as broad, lobes slightly narrowing; each lobe with three robust setae distally, with one long robust and one plumose seta marginally (Figure $5 \mathrm{H}$ ). 


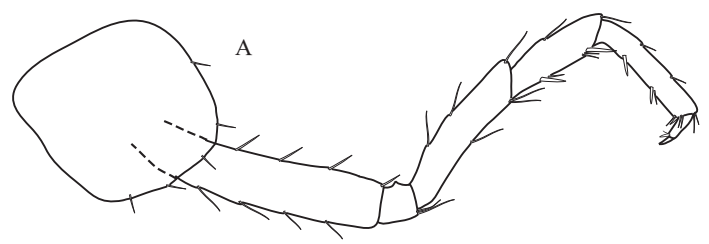

B

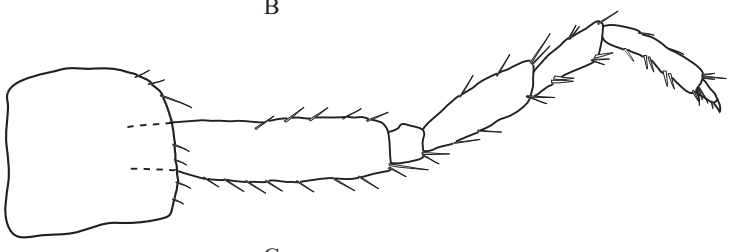

C

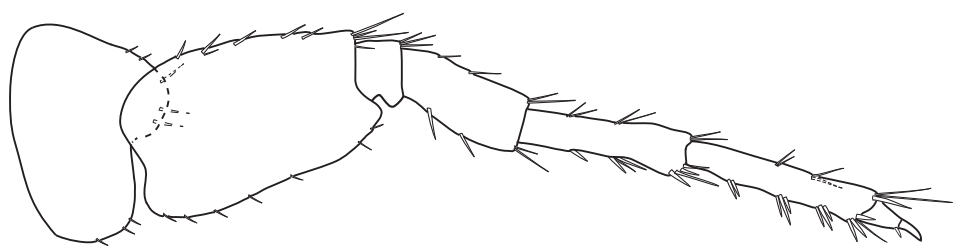

D
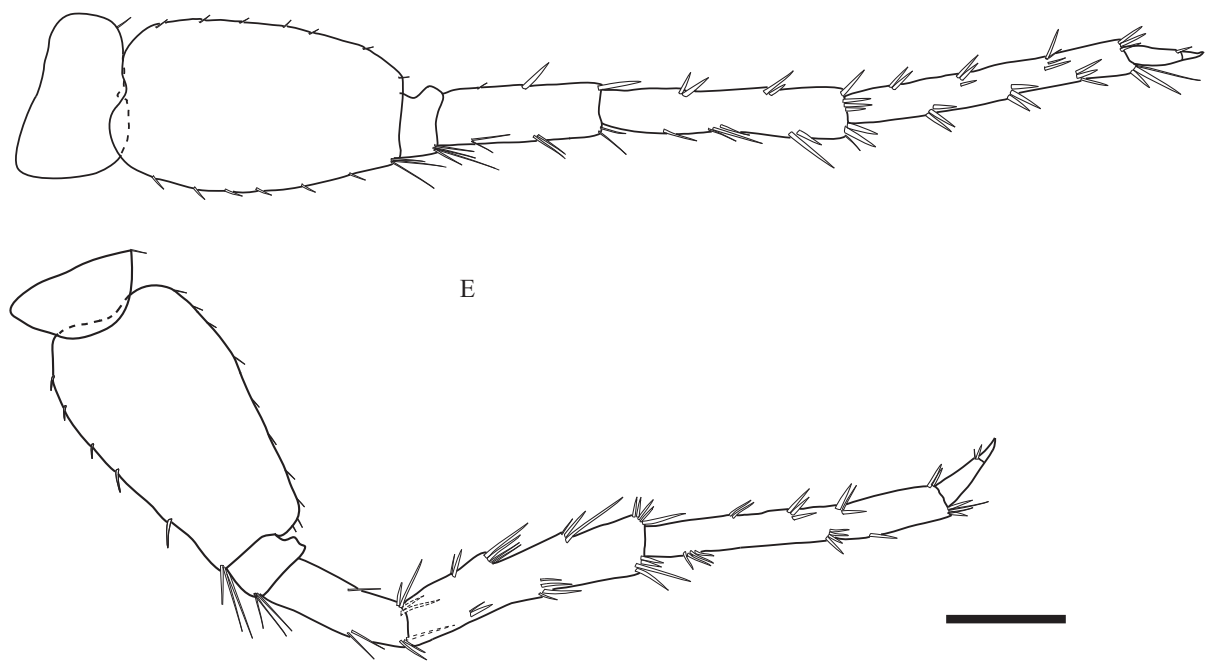

Figure 4. Niphargus hakani sp. n., male 9 mm (holotype, ZCRU Amph.1010). A Pereopod III B Pereopod IV C Pereopod V D Pereopod VI E Pereopod VII. Scale bars: $1 \mathrm{~mm}(\mathbf{A}-\mathbf{E})$.

Etymology. The name "hakani" refers to Hakan village where specimens were found.

Phylogenetic position of $N$. hakani sp. n. species. This species is nested within the main Iranian clade and apparently shares the nearest common ancestor with 

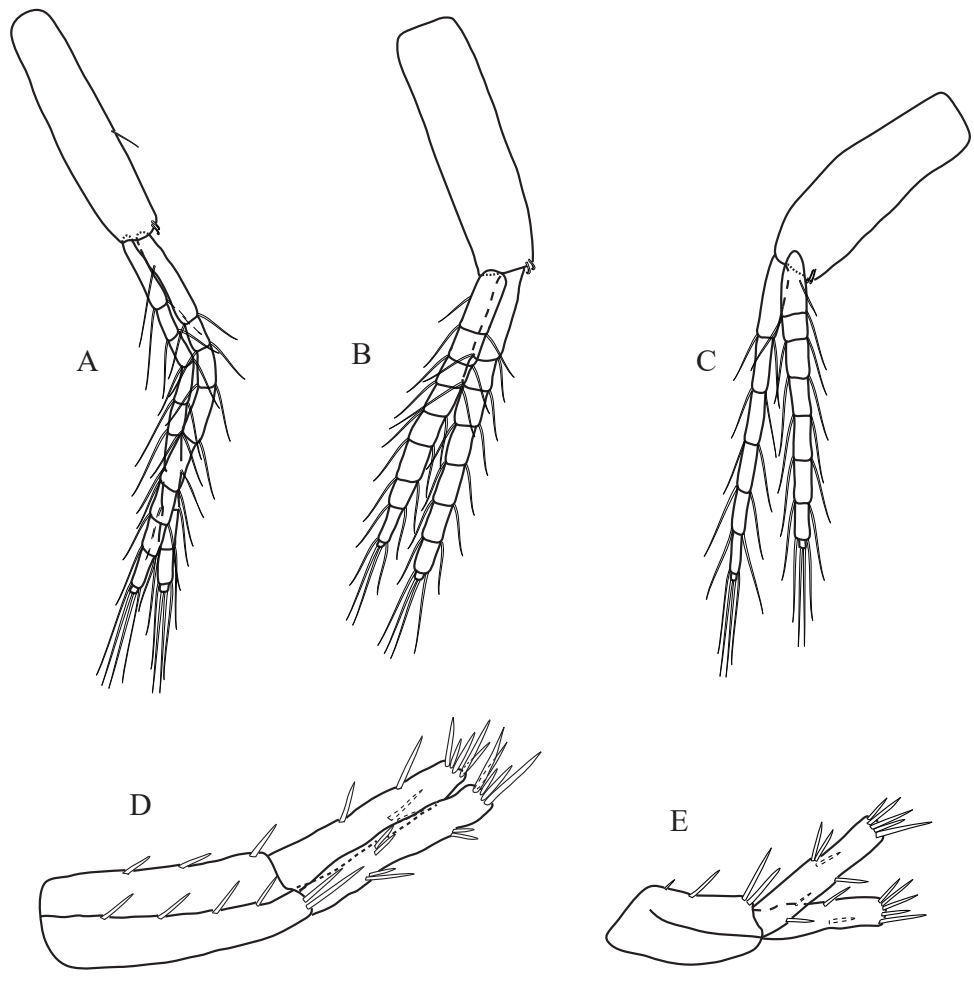

F
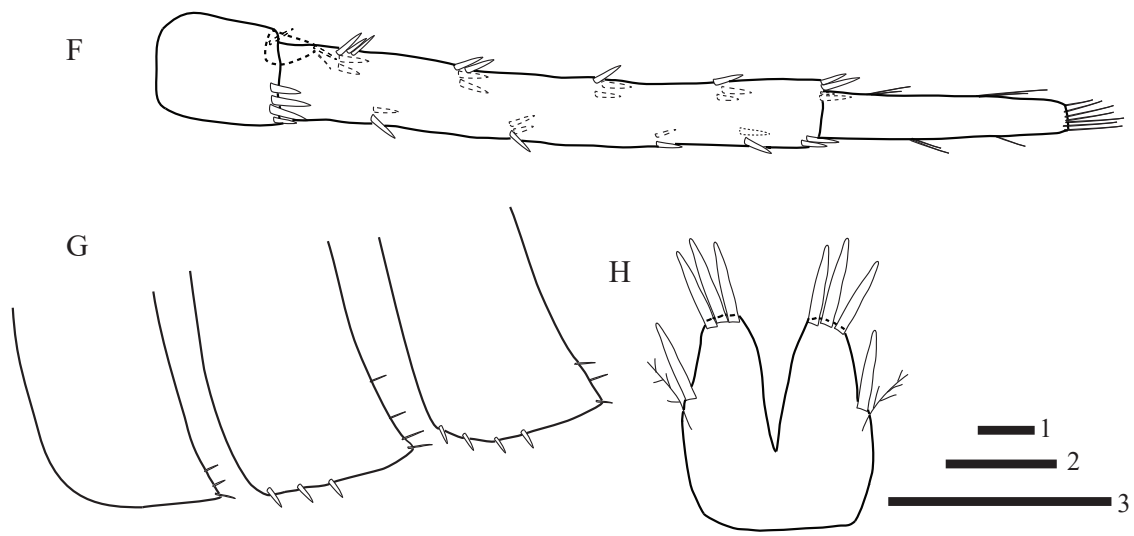

Figure 5. Niphargus hakani sp. n., male 9 mm (holotype, ZCRU Amph.1010). A Pleopod I B Pleopod II C Pleopod III D Uropod I E Uropod II F Uropod III. G Epimeral plates H Telson. Scale bars: $1=0.5 \mathrm{~mm}(\mathbf{G}-\mathbf{H}) .2=1 \mathrm{~mm}(\mathbf{A}-\mathbf{E}) .3=2 \mathrm{~mm} \mathbf{F}$.

N. khwarizmi, N. khayyami, N. kermanshahi and N. bisitunicus (Figure 6, please note weak node support). Among these, this species is genetically the most similar to $N$. khwarizmi (1.93\% K2P divergence in the studied $28 \mathrm{rDNA}$ gene fragment) and the most divergent species from $N$. bisitunicus, (2.20\% K2P divergence). 


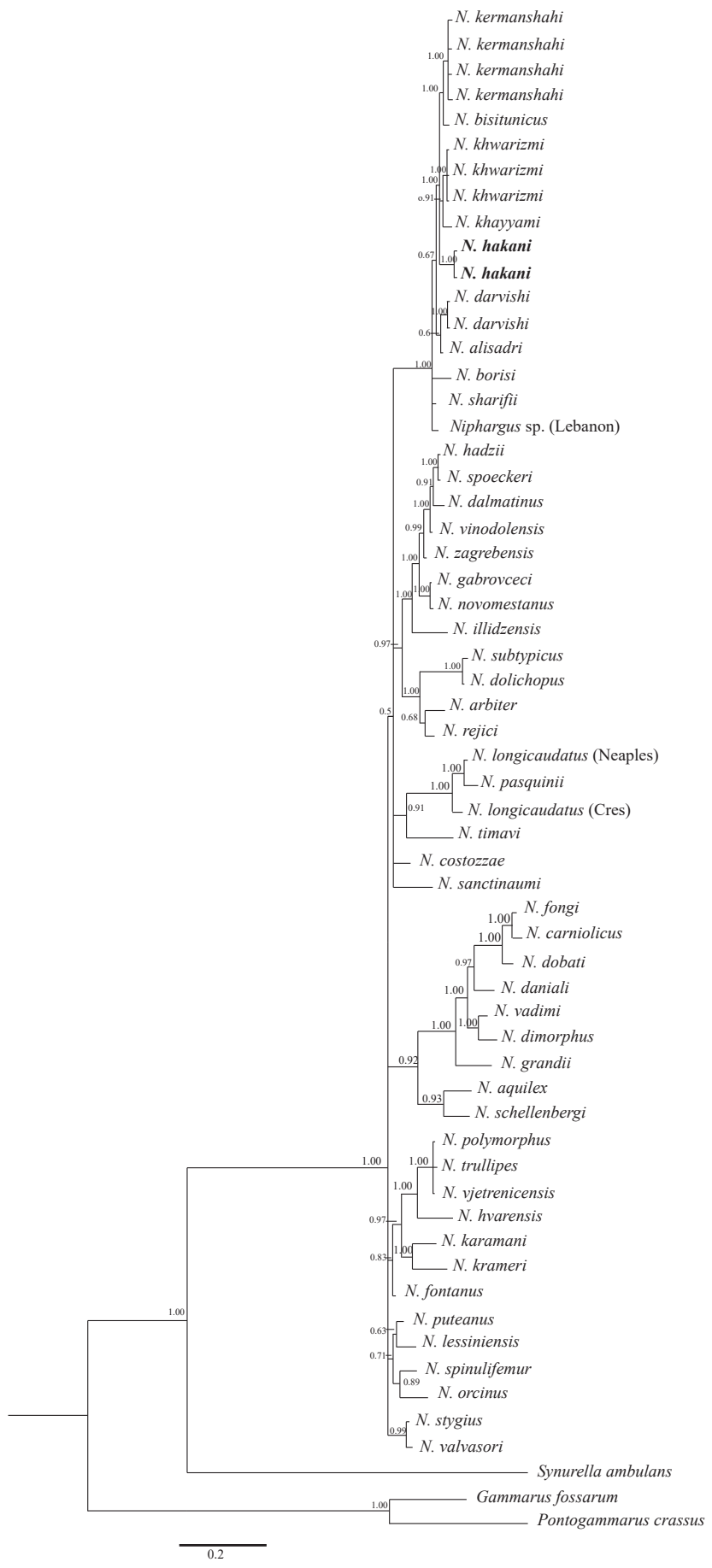

Figure 6. Bayesian consensus tree of 49 Niphargus species (48 taxa from Esmaeili-Rineh et al. 2015a, 2016), based on the 28 S ribosomal DNA sequences. Species are identified and named according to the valid taxonomic description. Posterior probabilities are indicated on main branches. 


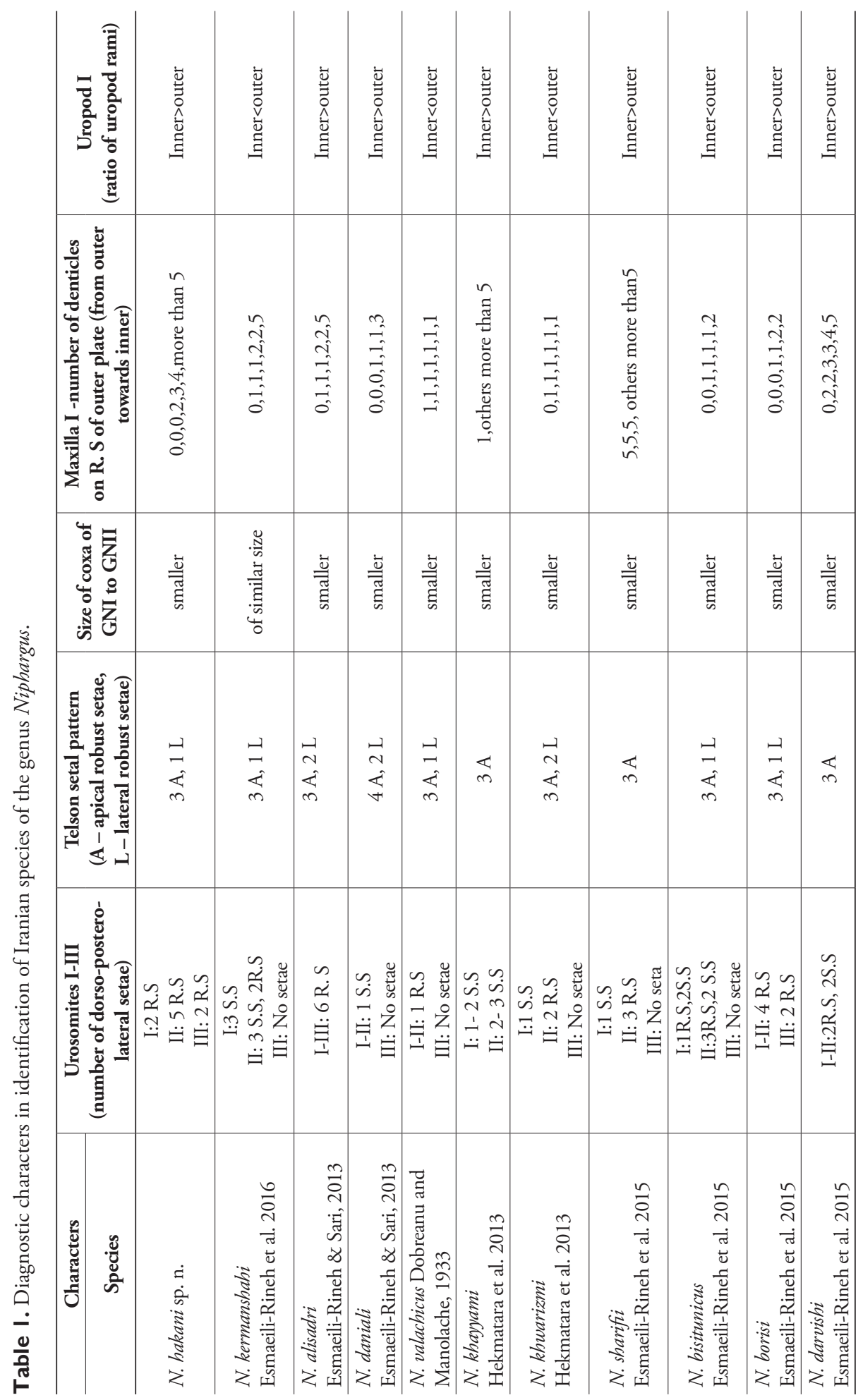




\begin{tabular}{|c|c|c|c|c|c|c|c|c|c|c|c|}
\hline 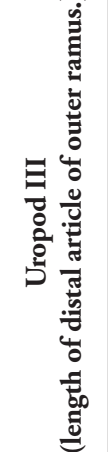 & 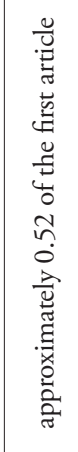 & 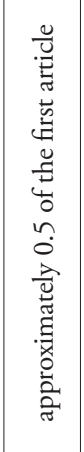 & 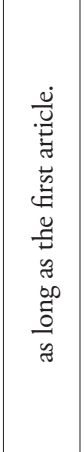 & 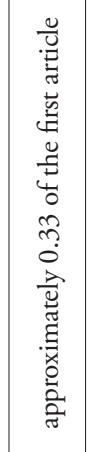 & 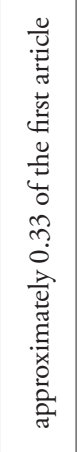 & 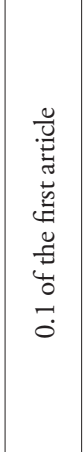 & 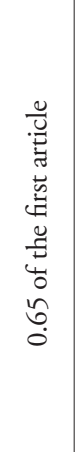 & 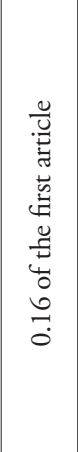 & 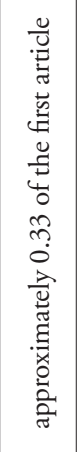 & 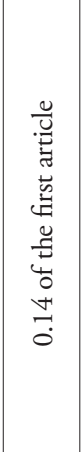 & 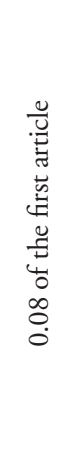 \\
\hline 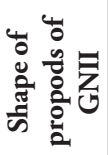 & 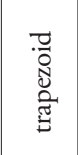 & 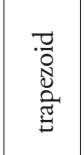 & 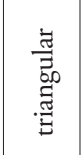 & 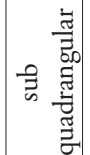 & $\begin{array}{l}\overline{0} \\
\overline{0} \\
\tilde{\Xi} \\
\tilde{\Xi}\end{array}$ & 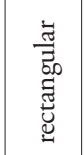 & 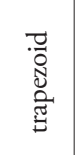 & 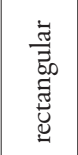 & 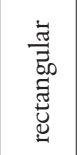 & 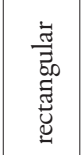 & 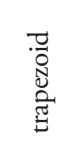 \\
\hline 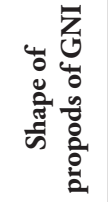 & $\begin{array}{l}\overline{\overrightarrow{0}} \\
0 \\
\overline{0} \\
\tilde{\Xi}\end{array}$ & 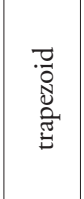 & 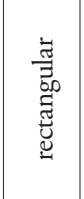 & 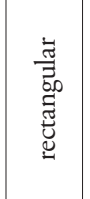 & $\begin{array}{l}\overline{0} \\
\overline{0} \\
\overline{0} \\
\text { ज्ञ }\end{array}$ & 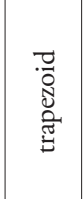 & 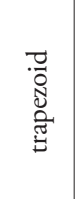 & 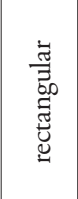 & 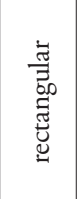 & 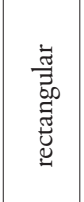 & 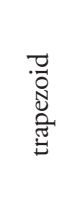 \\
\hline 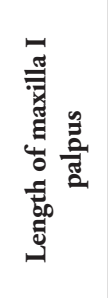 & 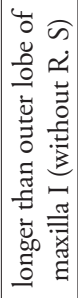 & 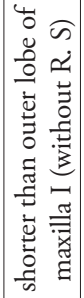 & 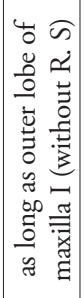 & 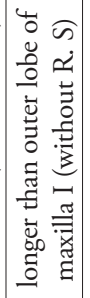 & 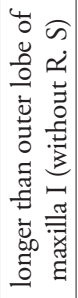 & 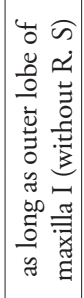 & 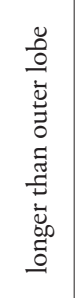 & 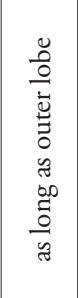 & 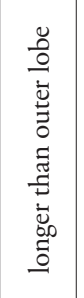 & 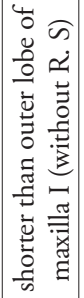 & 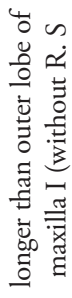 \\
\hline 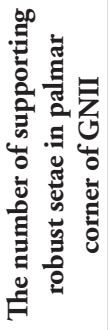 & - & $\sim$ & $n$ & - & - & - & - & $N$ & $N$ & $m$ & - \\
\hline 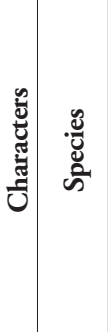 & $\begin{array}{l}\dot{a} \\
\dot{2} \\
\dot{z} \\
z \\
z \\
z \\
\dot{z}\end{array}$ & 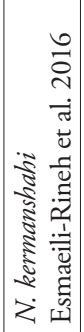 & 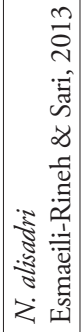 & 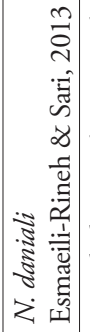 & 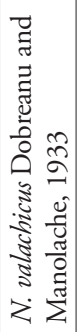 & 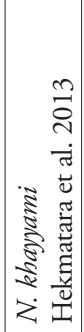 & 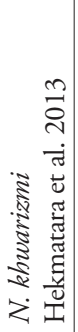 & 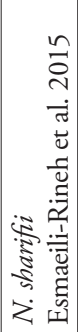 & 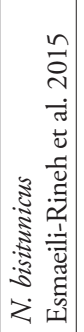 & 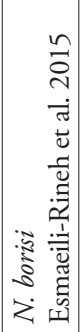 & 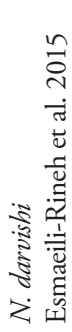 \\
\hline
\end{tabular}




\section{Discussion}

Niphargus hakani sp. n. is a member of the main Iranian clade (Esmaeili-Rineh et al. 2015a) and shares common ancestry with $N$. khwarizmi, N. khayyami, N. kermanshahi and $N$. bisitunicus. The closest relative seems to be $N$. khwarizmi. Although $N$. hakani sp. n. shares relative length of palpus of maxilla I, shape of propodus of gnathopods and ratio of second to first article of outer ramus of uropod III. However, this species differs from $N$. khwarizmi in the fewer lateral robust setae in telson, ratio of inner to outer ramus of uropod I and ornamentation of lateral projection of robust setae in outer plate of maxilla I (Hekmatara et al. 2013). A shortened list of diagnostic traits for the Iranian species is presented in Table 1. Niphargus khayyami differs from $N$. hakani by ratio of distal to proximal article of outer ramus of uropod III, number of apical robust setae on telson and multidenticulated robust setae on the outer plate of maxilla I.

An important diagnostic traits of $N$. hakani sp. $\mathrm{n}$. is the presence of robust setae on urosomite III. This character was observed in N. borisi and N. alisadri from Iran and some species from Europe including $N$. croaticus Sket, 1958, N. trullipes (Jurinac, 1887), and $N$. hercegovinensis S. Karaman, 1950 (Karaman 1984). Niphargus borisi resembles $N$. hakani sp. n. also in shape of postero-ventral angle of epimeral plates; but differs from herein described species in higher number of robust setae at the base of uropod I, the shape of propodus of gnathopods and in the elevated number of supporting robust setae in palmar corner of gnathopod I (Esmaeili-Rineh et al. 2015b). Niphargus alisadri, the second species sharing spiny urosomite III with $N$. hakani sp. n. differs from this species in ratio of distal to proximal article of outer ramus in uropod III, the increased number of lateral robust setae in telson and the ratio of palpus to outer plate length in maxilla I (Esmaeili-Rineh and Sari 2013).

\section{Conclusion}

We described new taxon of Iranian Niphargus. Iranian niphargid fauna now counts 11 species, all but $N$. valachicus being endemic to Iran. We expect that further explorations will unveil additional new species from rich biodiversity in this area.

\section{Acknowledgments}

This project was funded by the Iran National Science Foundation (INSF-92033591). Authors are grateful to Razi University for providing the fieldwork facilities. We are especially grateful to two anonymous referees for their valuable comments. 


\section{References}

Bousfield EL (1977) A new look at the systematics of gammaridean amphipods of the world. Crustaceana supplement 4: 282-316.

Dobreanu E, Manolache C (1933) Beitrag zur kenntnis der Amphipoden Rumniens. Notationes Biologicae. Bucarest: 103-108.

Esmaeili-Rineh S, Sari A (2013) Two new species of Niphargus Schiödte, 1849 (Crustacea: Amphipoda: Niphargidae) from two caves in Iran. Journal of Natural History 47: 2649-2669. https://doi.org/10.1080/00222933.2013.802041

Esmaeili-Rineh S, Sari A, Delić T, Moškrič A, Fišer C (2015a) Molecular Phylogeny of the Subterranean Genus Niphargus (Crustacea: Amphipoda) in the Middle East: A Comparison with European Niphargids. Zoological Journal of the Linnaean Society 175: 812-826. https://doi.org/10.1111/zoj.12296

Esmaeili-Rineh S, Sari A, Fišer C (2015b) Making future taxonomy of Niphargus (Crustacea: Amphipoda: Niphargidae) in the Middle East easier: DELTA database of Middle East species with description of four new species from Iran. Zootaxa 4020: 401-430. https://doi. org/10.11646/zootaxa.4020.3.1

Esmaeili-Rineh S, Heidari F, Fišer C, Akmali V (2016) Description of new endemic species of the genus Niphargus Schiödte, 1849 (Amphipoda: Niphargidae) from a karst spring in Zagros Mountains in Iran. Zootaxa 4126: 338-350. https://doi.org/10.11646/ zootaxa.4126.3.2

Fišer C, Sket B, Trontelj P (2008) A phylogenetic perspective on 160 years of troubled taxonomy of Niphargus (Crustacea: Amphipoda). Zoologica Scripta 37: 665-680. https://doi. org/10.1111/j.1463-6409.2008.00347.x

Fišer C, Trontelj P, Luštrik R, Sket B (2009) Toward a unified taxonomy of Niphargus (Crustacea: Amphipoda): a review of morphological variability. Zootaxa 2061: 1-22.

Hall TA (1999) BioEdit: a user-friendly biological sequence alignment editor and analysis program for Windows 95/98/NT. Nucleic Acids Symposium Series 41: 95-98.

Hekmatara M, Zakšek V, Heidari MB, Fišer C (2013) Two new species of Niphargus (Crustacea: Amphipoda) from Iran. Journal of Natural History 47: 1421-1449. https://doi.org /10.1080/00222933.2012.743616

Hou Z, Li S (2010) Intraspecific or interspecific variation: delimitation of species boundaries within the genus Gammarus (Crustacea, Amphipoda, Gammaridae), with description of four new species. Zoological Journal of the Linnaean Society 260: 215-253. https://doi. org/10.1111/j.1096-3642.2009.00603.x

Huelsenbeck JP, Ronquist F (2001) MrBayes: Bayesian inference of phylogenetic trees. Bioinformatics 17: 754-755. https://doi.org/10.1093/bioinformatics/17.8.754

Jones R, Culver DC, Kane TC (1992) Are parallel morphologies of cave organisms the result of similar selection pressures?. Evolution 46: 353-365. https://doi.org/10.2307/2409856

Karaman GS (1984) Revision of the Niphargus orcinus-group, part I. (fam. Niphargidae) (Contribution to the Knowledge of the Amphipoda 130). The Montenegrin Academy of Sciences and Arts: Glasnik Section of Natural Sciences 4: 7-79. 
Karaman GS (1998) First discovery of the family Niphargidae (Gammaridea) in Iran (contribution to the knowledge of the Amphipoda 243). Glas Od Pr Glasnik Odjeljenja Prirodnih Nauka-Crnog Akad Nauka Umjet 12: 9-22.

Kimura M (1980) A simple method for estimating evolutionary rate of base substitutions through comparative studies of nucleotide sequences. Journal of Molecular Evolution 16: 111-120. https://doi.org/10.1007/BF01731581

Latreille PA (1816) Amphipoda. In: Nouveau Dictionaire d'histoire naturelle, appliquée aux Arts, à l'Agriculture, à l'Économie rurale et domestique, à la Médecine, etc. Par une société de Naturalistes et d'Agriculteurs. 2nd ed. Deterville, Paris.

Lowry JK, Myers AA (2013) A phylogeny and Classification of the Senticaudata subord. nov. (Crustacea: Amphipoda). Zootaxa 3610: 1-80. https://doi.org/10.11646/zootaxa.3610.1.1

Posada D (2008) jModelTest: Phylogenetic model averaging. Molecular Biology and Evolution 25: 1253-1256. https://doi.org/10.1093/molbev/msn083

Rambaut A, Drummond AJ (2009) Bayesian Evolutionary Analysis Sampling Trees (BEAST). Version 1.7.4.

Ronquist F, Huelsenbeck JP (2003) MrBayes 3: Bayesian phylogenetic inference under mixed models. Bioinformatics 19: 1572-1574. https://doi.org/10.1093/bioinformatics/btg180

Schiödte JG (1849) Bidrag til den underjordiske fauna. Det kong danske vidensk Selsk krifter Femte Raekke Naturv Mathem Afd Andet Bind. Copenhagen.

Tamura K, Peterson D, Peterson N, Stecher G, Nei M, Kumar S (2011) MEGA5: Molecular Evolutionary Genetics Analysis using Maximum Likelihood, Evolutionary Distance, and Maximum Parsimony Methods. Molecular Biology and Evolution 28: 2731-2739. https://doi.org/10.1093/molbev/msr121

Thompson JD, Higgins DG, Gibson T (1994) Clustal W: improving the sensitivity of progressive multiple sequence alignment through sequence weighting, position specific gap penalties and weight matrix choice. Nucleic Acids Research 22: 4673-4680. https://doi. org/10.1093/nar/22.22.4673

Verovnik R, Sket B, Trontelj P (2005) The colonization of Europe by the freshwater crustacean Asellus aquaticus (Crustacea: Isopoda) proceeded from ancient refugia and was directed by habitat connectivity. Molecular Ecology 14: 4355-4369. https://doi.org/10.1111/j.1365294X.2005.02745.x

Zakšek V, Sket B, Trontelj P (2007) Phylogeny of the cave shrimp Troglocaris: evidence of a young connection between Balkans and Caucasus. Molecular Phylogenetics and Evolution 42: 223-235. https://doi.org/10.1016/j.ympev.2006.07.009 